\title{
"Para que Serve Lêr e Escrever?" O Depoimento de Alunos e Professores
}

\author{
Alina Galvão Spinillo \\ Eliana Borges C. de Albuquerque \\ Universidade Federal de Pernambuco (UFPE) \\ Maria Emilia Lins e Silva \\ Universidade Federal da Paraíba (UFPB)
}

O depoimento de alunos e professores de alfabetização de escolas públicas e particulares acerca dos usos e funções da linguagem escrita foi analisado a partir de entrevistas onde a pergunta central era: "Para que serve 1er e escrever?" Pelos depoimentos foi possível identificar diferentes concepções, as quais variam entre professores e alunos e em função do tipo de escola. A natureza dessas concepções reflete noções distintas a respeito dos usos e funções da linguagem escrita para o indivíduo que aprende a 1er e a escrever.

\section{Introdução}

Os aspectos funcionais da linguagem são documentados por diversos pesquisadores. Comparações conduzidas entre crianças de classes sociais distintas (e.g., Moreira, 1988; Soares, 1988) ou até mesmo de meios culturais diferentes (e.g., Labov, 1972; Heath, 1983; Hicks, 1991) indicam que diferenças socioculturais contribuem para concepções, usos, funções e conhecimentos distintos a respeito da linguagem oral e escrita. Neste artigo, é inicialmente abordada a maneira como a linguagem escrita é tratada no contexto escolar,

. bras. Est. pedag., Brasília, v.77, n.I87, p.477-496, set./dez. 1996 
durante o processo de alfabetização, e corno a criança atribui funções aos portadores de texto comumente veiculados em nossa sociedade. Em seguida, os aspectos funcionais da linguagem escrita são discutidos à luz do. depoimento de alunos e professores de escolas públicas e particulares, analisando-se os usos e as funções atribuídos a este sistema de comunicação e registro.

\section{Usos e funções da escrita na escola}

A escola não tem contribuído para que as crianças de classe baixa ou média tenham uma concepção da linguagem escrita como uma forma de comunicação, e tampouco como instrumento para a apropriação de outros conhecimentos escolares. Os usos e as funções da língua escrita no contexto escolar diferem acentuadamente dos usos sociais da língua escrita no cotidiano de uma sociedade letrada. No contexto escolar, a língua escrita é tratada como

uma entidade abstraia, sem uma razão social que extrapole os objetivos puramente acadêmicos, retirando seu significado funcional. Os usos escolares da escrita parecem ser bastante restritos, ignorando sua dimensão comunicativa e menosprezando o seu papel como instrumento através do qual o indivíduo leitor tem acesso a outros conhecimentos (Spinillo, Roazzi, 1988, p.82).

Assim, no contexto escolar, a língua escrita não é concebida como um objeto cultural que cumpre funções sociais, mas como um fim em si mesma. Esta idéia é igualmente compartilhada por Soares (1988, p. 10), quando afirma que a escrita de textos na escola é:

um processo de desaprendizagem da escrita com as funções de interação autor/ leitor, de intersubjetividade, e de aprendizagem de uma escrita que, cm vez de interação, é reprodução de um modelo escolar de texto, é "prestação de contas" do autor a um leitor que nada mais espera senão reconhecer, no texto produzido, esse modelo; que, em vez de possibilidade de intersubjetividade é, ao contrário, negação da subjetividade de autor e leitor, porque um e outro se negam como sujeitos, na escrita/leitura do texto. (Gritos da autora). 
Rockwell (1985) observou o cotidiano de salas de aula em diversas séries do primeiro grau, verificando, entre outros aspectos, que a linguagem escrita raramente é utilizada para comunicar algo, ou como instrumento para a aquisição de outros conhecimentos que não ela própria. Rego (1988) enfatiza as diferenças entre a funcionalidade da linguagem escrita em sala de aula e no contexto familiar, demonstrando os limites que a prática alfabetizadora muitas vezes impõe à aquisição da leitura e da escrita por parte das crianças.

Recentemente, observações conduzidas em salas de alfabetização em escolas públicas e particulares da cidade do Recife (Spinillo, Albuquerque, Silva, 1992; Spinillo, 1994) demonstraram que, apesar das diferenças entre os dois sistemas de ensino, há inúmeras semelhanças entre si, semelhanças estas relativas à maneira como a língua escrita é tratada, em especial quanto à sua não funcionalidade no contexto escolar. Assim, adotando a expressão de Soares ( 1988), a aprendizagem da linguagem escrita na escola leva à desaprendizagem das funções da escrita.

\section{As concepções de crianças sobre a função de portadores de textos}

Moreira (1988, p.18-19) contrastou as concepções que crianças de classes sociais diferentes (média e baixa) teriam acerca das funções e dos conteúdos de diferentes portadores de textos. Por portadores de textos, a autora compreende os tipos de textos veiculados em uma sociedade letrada (e.g., jornal, revista, livros, receitas, rótulos de produtos, etc). As crianças, alunas de jardim e da $2^{\mathrm{a}}$ série do primeiro grau, eram solicitadas a identificar diferentes portadores de textos, indicando as pistas que utilizavam (critérios) para sua identificação, especificando qual a função daquele portador, predizendo seu conteúdo. Tendo por base o método clínico piagetiano, as erguntas endereçadas às crianças versavam sobre: 1. Identificação do portador: "Queria que você me desse o mapa (ou o jornal, a revista, a carta, etc.)". 
2. Identificação dos atributos: "como você sabe que isto é um mapa?"

3. Especificação da função: "Para que serve o mapa?"

4. Predição de conteúdo: "O que você acha que está escrito no mapa?"

O dado que mais nos interessa neste estudo refere-se ao item 3, acerca da especificação da função dos portadores de texto. Analisando as respostas relativas às perguntas deste item, a autora sugere a existência de níveis diferentes de concepção quanto aos usos ou funções comunicativas dos portadores de textos examinados.

Em um nível mais elementar, a função social do portador é percebida de modo contextualizado, referente a um traço da situação de uso, onde a leitura é percebida como um fim. Exemplos:

- o cartaz de propaganda política serve "para pregar na parede", "no guarda-roupa, no carro, no móvel. Prega para enfeitar"(p.32);

- a carta serve "pra dar pra mãe, pra dizer que é pra receber dinheiro" (p.34);

- o jornal serve "pro papai 1er" (p.34).

Em um nível mais elaborado, a função social do texto é percebida e aparece sobretudo entre os portadores mais familiares das crianças (e.g., rótulo de leite, receita de bolo, jornal). São respostas relacionadas à função comunicativo-social do portador, e a função da leitura é percebida como um meio para se obter algo mais que extrapola o próprio texto. Exemplos:

- o cartaz de propaganda política serve "pra fazer política eleitoral. Usa em parede pra fazer votar" (p.33);

- o jornal serve "pra saber o que acontece dentro e fora do Brasil: quem morre, quem rouba..." (p.33).

As crianças de classe baixa, do jardim, forneciam $71 \%$ de respostas elementares e apenas $29 \%$ de respostas elaboradas, enquanto as crianças de mesma série, de classe média, forneciam $43 \%$ de respostas elementares e $57 \%$ de respostas elaboradas. Esta mesma diferença foi também notada na $2^{\mathrm{a}}$ série, onde as crianças de classe baixa forneciam $49 \%$ de respostas 
elementares e $51 \%$ de respostas elaboradas; enquanto as de classe média forneciam apenas $13 \%$ de respostas elementares e $87 \%$ de respostas elaboradas. Em ambos os grupos de idade, verifica-se uma superioridade das crianças de classe média sobre as de classe baixa quanto à especificação das funções dos portadores de texto. Embora todas as crianças apresentassem, desde o início, alguma noção acerca das funções desses portadores, essa compreensão parece estar fortemente relacionada à origem socioeconòmica da criança, o que gera diferentes níveis de familiaridade com os portadores de texto, níveis esses que se refletem nos tipos de respostas fornecidas pelas crianças.

\section{Aspectos motivacionais}

A familiaridade com a linguagem escrita não determina apenas o nível de compreensão que a criança tem sobre as funções desse tipo de registro, mas também parece contribuir para os níveis motivacionais que a levam para a aprendizagem da leitura e da escrita, como mencionado por Carraher $(1984,1986)$. Segundo a autora, crianças de classe média e alta estariam motivadas para essa aprendizagem, por encontrarem usos imediatos para a linguagem escrita em suas vidas; enquanto as crianças de classe baixa veriam na linguagem escrita apenas a possibilidade de se livrar do analfabetismo, não apresentando, portanto, a mesma motivação.

Assim, diferenças entre classes sociais geram diferentes concepções e conhecimentos a respeito da linguagem escrita. As oportunidades de uso e contato com o mundo da escrita determinam, também, níveis motivacionais distintos para o aprendizado da leitura e da escrita. A escola, tanto pública como particular, parece estar longe de criar em sala de aula um contexto e interações em que 1er e escrever sejam atos comunicativos mediante os quais se constróem e se produzem significados, e que permitem o acesso a conhecimentos diversos. 
Desta forma, parece importante investigar de maneira mais detalhada as concepções de crianças acerca da funcionalidade da escrita. Este é o principal objetivo do presente estudo, onde se procurou explorar essas concepções a partir do depoimento das próprias crianças acerca da importância, dos usos e das funções que elas atribuem à linguagem escrita. Foram examinadas, ainda, as concepções de professores alfabetizadores das redes de ensino público e particular. Teriam professores e crianças diferentes concepções acerca dos usos e das funções da linguagem escrita? Haveria diferenças entre crianças de classe baixa e de classe média quanto a este aspecto? Professores de escola pública e professores de escolas particulares pensam diferentemente acerca deste aspecto?

\section{Método}

A metodologia utilizada consistiu de entrevistas individuais com crianças de alfabetização de classe média e baixa e seus professores (de escolas públicas e particulares). Um total de 21 escolas públicas e 20 particulares participaram do estudo.

\section{SUJEITOS}

Os alunos: Um total de 64 crianças, de ambos os sexos, alunas de alfabetização. Trinta e duas eram alunas de escolas públicas e 32 de escolas particulares da cidade do Recife. A idade das crianças variava de 6 a 7 anos, nas escolas particulares, e de 7 a 12 anos nas escolas públicas.

Os professores: Um total de 60 professoras alfabetizadoras, $30 \mathrm{de}$ escolas públicas e 30 de escolas particulares da cidade do Recife, com idades entre 20 e 40 anos. A experiência dessas professoras em salas de alfabetização variava de um a quinze anos, as quais ensinavam nas mesmas escolas freqüentadas pelas crianças entrevistadas. 
Os sujeitos foram entrevistados individualmente, tendo como base da entrevista a pergunta: "Para que serve 1er e escrever?". Esta pergunta tinha por objetivo examinar os usos e as funções atribuídos à linguagem escrita pelo entrevistado. Outras perguntas foram formuladas para estimular os depoimentos ou para esclarecer melhor as respostas apresentadas. As respostas foram gravadas e registradas, havendo espaço para quaisquer outros comentários que o entrevistado desejasse fazer.

\section{Classificação das respostas}

\section{TIPOS DE RESPOSTAS}

Os depoimentos dos entrevistados foram agrupados em seis tipos de respostas, que refletem suas concepções acerca dos usos e das funções atribuídos à linguagem escrita. Muitas vezes ocorria de um mesmo entrevistado oferecer mais de um tipo de resposta em seu depoimento. Os tipos de respostas são explicitados e exemplificados a seguir:

Tipo 1 - Usos extra-escolares: realizar atividades da vida diária fora do contexto escolar. Três modalidades de respostas foram identificadas:

1. Extensão da memória: anotar recados, registrar informações (telefones, endereços, etc). Exemplos:

"Para escrever o nome da rua."

"Para escrever o nome e o telefone da pessoa, para não esquecer."

2. Comunicação através da escrita (1er e escrever cartas, bilhetes, 1er jornais, revistas, etc). Exemplos: 
"Mandar o bilhete."

"Para 1er revista, jornal, livro, contar história."

3. Auxiliar no desempenho de atividades práticas (pegar ônibus, 1er placas, preparar alimentos, etc). Exemplos:

"Para apanhar ônibus e não ficar perguntando."

"Ler as placas, os avisos na rua."

Tipo 2 - Usos escolares: realizar atividades próprias da cultura escolar. Quatro modalidades de respostas foram identificadas:

1. Um fim em si mesmo. Exemplo:

"Para 1er e escrever."

2. Para fazer avaliações, tarefas e exercícios escolares. Exemplos:

"Para a tia dar um 10."

"Para fazer o dever."

"Facilita a realização das tarefas."

"Para estudar."

3. Condição para a passagem de uma série a outra. Exemplos:

"Para passar de ano."

"Passar para a $1^{a}$ série, passar para outra classe depois, e para outra, para outra, bem longe, até o ginásio."

4. De natureza disciplinar. Exemplos:

"com a escrita e a leitura o aluno se torna mais dócil, disciplinado."

"Para a tia não reclamar com a gente, para a gente poder recrear, para a gente fazer rápido, para ir para o parque e não deixar tarefa na mesa."

Tipo 3 - Objetivos futuros: relativo ao que se pode alcançar em nível individual (conseguir um emprego, melhorar de vida, etc), estando relacionada à aquisição de objetivos futuros. Exemplos:

"Para conseguir uma profissão."

"Para quando estiver grande, trabalhar."

"Para ser alguma coisa na vida."

"Ter maiores possibilidades de uma vida melhor e uma maior chance de conseguir um emprego."

"Para ter um futuro melhor. Abre novos horizontes." 
Tipo 4 - Instrumento de transformação social: a leitura e a escrita são percebidas como um instrumento por meio do qual o indivíduo se torna um cidadão, compreende a realidade e a transforma. Exemplos:

"Para conhecimento de seus direitos e deveres."

Compreender a realidade oprimida." "Para ter consciência crítica." "Para o desenvolvimento da sociedade." "Para transformar a sociedade." Tipo 5 Instrumento para obter conhecimentos: a leitura e a escrita são consideradas como um instrumento por meio do qual o indivíduo pode apropriar-se de informações e conhecimentos. Entretanto, essas informações e esses conhecimentos são colocados de forma geral e vaga. Exemplos:

"Para ter cultura e conhecimentos."

"Para saber dos assuntos."

"Para ter informações, sobre tudo sobre fatos."

Tipo 6 - Amplificador de habilidades intelectuais e instrumento de socialização: a leitura e a escrita são percebidas como algo que determina a aquisição de habilidades cognitivas. Seria, portanto, um instrumento mediante o qual o usuário se tornaria intelectual e socialmente mais competente. Exemplos:

"Para proporcionar uma melhor socialização entre as pessoas."

"Melhorar o intelecto."

"Para não ficar burro, para ser inteligente."

"Para melhorar o pensamento da pessoa."

"Para se comunicar."

"Para conviver, se entrosar."

R. bras. Est. pedag., Brasilia, v.77, n.187, p.477-496, set./dez. 1996 


\section{Resultados}

Existiriam diferenças entre os usos e as funções atribuídos à linguagem escrita entre: a) alunos de classe baixa e alunos de classe média; b) entre professores de escolas públicas e particulares; c) entre os depoimentos de alunos e professoras de uma mesma rede de ensino?

Os resultados indicam que os usos e as funções atribuídos à linguagem escrita diferem entre alunos e professores de ambas as escolas, como ilustrado na Tabela 1.

Tabela 1 - Porcentagem de entrevistados em cada tipo de resposta

\begin{tabular}{|c|c|c|c|c|}
\hline \multirow[b]{2}{*}{ Resposta } & \multicolumn{2}{|c|}{ Púb ica } & \multicolumn{2}{|c|}{ Particular } \\
\hline & $\begin{array}{l}\text { Aluno } \\
(\mathrm{N}=32)\end{array}$ & $\begin{array}{l}\text { Professor } \\
(\mathrm{N}=30)\end{array}$ & $\begin{array}{l}\text { Aluno } \\
(\mathrm{N}=32)\end{array}$ & $\begin{array}{l}\text { Professor } \\
(\mathrm{N}=30)\end{array}$ \\
\hline $\begin{array}{ll}\text { escolar } & 1 \text { Uso extra- }\end{array}$ & 25 & 20 & 9 & 3 \\
\hline $\begin{array}{l}2 \text { Uso } \\
\text { escolar }\end{array}$ & 31 & 3 & 63 & 13 \\
\hline $\begin{array}{c}3 \\
\text { Objetivo futuro }\end{array}$ & 75 & 13 & 16 & 23 \\
\hline social 4 Transformação & 0 & 53 & 0 & 7 \\
\hline $\begin{array}{c}5 \\
\text { Conhecimento }\end{array}$ & 0 & 10 & 0 & 20 \\
\hline $\begin{array}{l}\text { 6 Habilidade } \\
\text { intelectual }\end{array}$ & 16 & 33 & 44 & 53 \\
\hline
\end{tabular}

Nota: Um mesmo entrevistado podia fornecer mais de um tipo de resposta em seu depoimento, justificándose, assim, as porcentagens somadas em cada coluna não resultarem em $100 \%$. 
Os depoimentos de alunos das escolas públicas e particulares diferem significativamente $(\mathrm{p}<001)$. Setenta e cinco por cento dos alunos das escolas públicas forneceram respostas Tipo 3 (Objetivos Futuros) e 63\% dos alunos das escolas particulares deram respostas Tipo 2 (Usos Escolares). Enquanto que para os alunos de escolas públicas a linguagem escrita é percebida como um instrumento que o auxiliará no alcance de objetivos futuros, os alunos das escolas particulares acreditam que a língua escrita é fundamentalmente usada para realizar as tarefas escolares.

Diferenças também foram encontradas entre os depoimentos dos professores $(p<.01)$. Cinqüenta e três por cento dos professores das escolas públicas conferem à escrita o papel de instrumento de transformação social (Tipo 4), enquanto 53\% dos professores das escolas particulares acreditam que esta seria capaz de ampliar as habilidades cognitivas de seus usuários (Tipo 6). Assim, professores que lidam com crianças de classe social baixa ressaltam a natureza social e política envolvida na aquisição da linguagem escrita; enquanto os professores que lidam com crianças de classe média e alta tendem a enfatizar os ganhos individuais do ponto de vista intelectual, que se obtêm quando se aprende a ler e a escrever.

\section{ANÁLISE INTRA-ESCOLAS: PROFESSORES X ALUNOS}

Comparando-se os depoimentos de alunos e professores nas escolas públicas, foi possível detectar uma diferença significativa $(\mathrm{p}<.001)$. Esta diferença decorre do fato de que para os alunos a funcionalidade da língua escrita está relacionada a objetivos futuros (Tipo 3 - 75\%), enquanto que para os professores a funcionalidade é basicamente de transformação social (Tipo 4-53\%).

Em relação aos depoimentos de alunos e professores das escolas particulares, também foi possível detectar uma diferença significativa $(p<.01)$ entre eles. Esta diferença existe porque, para os alunos, a leitura e a escrita possuem uma função acadêmica (Tipo 2 - 63\%), enquanto que para os 
professores esta funcionalidade está relacionada ao desenvolvimento individual do aluno (53\% - Tipo 6). Assim, alunos diferem de professores em cada escola.

O QUE O INDIVÍDUO PODE FAZER com A LÍNGUA ESCRITA (USOS) E O QUE A LÍNGUA ESCRITA PODE FAZER PELO INDIVÍDUO (FUNÇÕES)

Os diferentes tipos de respostas encontrados nos depoimentos dos enrevistados demonstram que à linguagem escrita podem ser atribuídos usos e funções diversos. Os usos especificam aquilo que o indivíduo pode fazer com a língua escrita (exemplo: pegar ônibus, fazer tarefas), enquanto as funções especificam aquilo que a língua escrita pode fazer pelo indivíduo (exemplo: torná-lo agente transformador da sociedade, intelectualmente mais competente), como especificado por Carraher (1986, p.70). Considerando esses dois aspectos (usos e funções), é possível combinar os seis tipos de respostas em dois grupos: respostas relativas aos usos (Tipos 1 e 2) e respostas relativas às funções (Tipos $3,4,5$ e 6 ). As porcentagens de entrevistados que atribuíram usos e funções à linguagem escrita são apresentadas na Tabela 2.

Tabela 2 - Porcentagem de entrevistados que forneceram respostas relativas aos usos que o indivíduo atribui à linguagem escrita (o que ele faz com ela) e às funções (o que ela pode fazer pelo indivíduo)

\begin{tabular}{c|c|c|c|c}
\hline \multirow{2}{*}{ Ganhos } & \multicolumn{2}{|c|}{ Pública } & \multicolumn{2}{c}{ Particular } \\
\cline { 2 - 5 } & Aluno & Professor & Aluno & Professor \\
\hline $\begin{array}{c}\text { U sos } \\
(1,2)\end{array}$ & 56 & 23 & 72 & 16 \\
\hline $\begin{array}{c}\text { Funções (3, } \\
4,5 \text { e 6) }\end{array}$ & 91 & 100 & 60 & 100 \\
\hline
\end{tabular}

Nota: Um mesmo entrevistado podia fornecer mais de um tipo de resposta $\mathrm{cm}$ seu depoimento, justificando-se, assim, as porcentagens somadas em cada coluna não resultarem em $100 \%$. 
Os professores de ambas as escolas tendem, igualmente, a enfatizar mais as funções da linguagem escrita do que seus usos. Os alunos, entretanto, diferem entre si $(\mathrm{p}<.05)$. Os alunos das escolas públicas fornecem mais respostas ligadas às funções da escrita (escrita como instrumento, o que ela pode fazer pelo indivíduo) 'o que quanto aos seus usos, enquanto se observa o oposto entre os alunos das colas particulares.

Comparando-se os depoimentos em uma mesma escola, verifica-se que nas escolas públicas há concordância entre os depoimentos de alunos e professores, existindo uma tendência a enfatizar a linguagem escrita mais como um instrumento (função) do que quanto aos seus possíveis usos. Nas escolas particulares há certa divergência: os alunos tendem a enfatizar os usos da linguagem escrita e os professores, suas funções.

A NATUREZA DOS GANHOS A aquisição da linguagem escrita é percebida também como algo que pode trazer ganhos de natureza distinta: ganhos imediatos para seu usuário (Tipo 1: usos extra-escolares e Tipo 2: usos escolares), ganhos futuros (Tipos 3 e 4: emprego, transformação da sociedade) ou intelectuais (Tipos 5 e 6 : habilidades intelectuais). A Tabela 3 apresenta a porcentagem de entrevistados em função da natureza dos ganhos que o indivíduo pode obter mediante a leitura e a escrita.

Tabela 3 - Porcentagem de entrevistados que forneceram respostas relativas aos tipos de ganhos que o indivíduo obtém com a linguagem escrita

\begin{tabular}{l|c|c|c|c}
\hline Ganhos & \multicolumn{2}{|c|}{ Pública } & \multicolumn{2}{c}{ Particular } \\
\hline & Aluno & Professor & Aluno & Professor \\
\hline $\begin{array}{l}\text { Imediatos } \\
(1.2)\end{array}$ & 56 & 23 & 72 & 16 \\
\hline $\begin{array}{l}\text { Futuros } \\
\text { (341 }\end{array}$ & 75 & 66 & 16 & 30 \\
$\begin{array}{l}\text { Intelectuais } \\
(5,6)\end{array}$ & 16 & 43 & 14 & 73 \\
\hline
\end{tabular}

Nota: Um mesmo entrevistado podia fornecer mais de um tipo de resposta em seu depoimento, justificando-sc, assim, as porcentagens somadas em cada coluna não resultarem em $100 \%$.

R. bras. Est. pedag., Brasilia, v.77, n.187, p.477-496, set./dez. 1996 
Os professores, de um modo geral, raramente enfatizam os ganhos imediatos advindos da linguagem escrita. A diferença entre eles decorre do fato de que os professores das escolas públicas relacionam a aquisição da linguagem escrita a ganhos futuros, não enfatizando o papel desempenhado pela escrita como fator importante para o desenvolvimento de habilidades intelectuais. O oposto ocorre entre os professores das escolas particulares, para os quais o papel fundamental da linguagem escrita é o desenvolvimento dessas habilidades.

Quanto aos alunos, observa-se que os que freqüentam escolas públicas explicitam em seus depoimentos a estreita relação entre linguagem escrita e ganhos futuros. Os alunos das escolas particulares, por sua vez, associam a linguagem escrita a ganhos imediatos.

$\mathrm{Na}$ escola pública, tanto alunos como professores tendem a ressaltar os ganhos futuros que podem ser obtidos mediante a leitura e a escrita. $\mathrm{Na}$ escola particular, há diferenças entre os depoimentos de alunos e professores. Os alunos tendem a enfatizar os ganhos imediatos, e os professores acreditam que a linguagem escrita é fator importante para o desenvolvimento de habilidades intelectuais.

Assim, nas escolas públicas, a ênfase recai sobre os ganhos futuros derivados da aquisição da leitura e da escrita; e nas escolas particulares são enfatizados os ganhos intelectuais que podem ser obtidos por meio dessa aquisição.

\section{Discussão}

É possível tecer-se algumas considerações acerca dos usos e das funções atribuídos à linguagem escrita por parte de alunos e professores. A primeira conclusão refere-se ao fato de que parecem existir diferenças que sao determinadas pelo tipo de escola, e a segunda é que também existem diferenças entre as concepções de alunos e professores. 
$\mathrm{Na}$ escola publica, a escrita parece ser primeiramente concebida como um instrumento pelo qual se torna possível alcançar objetivos futuros e secundariamente como um instrumento de transformação social. Ela é considerada mais como um instrumento (função - o que a língua escrita pode fazer pelo individuo) do que como algo que tenha um uso imediato nas vidas de seus usuários (usos - o que o indivíduo pode fazer com a íngua escrita). A natureza dos ganhos basicamente envolve os ganhos futuros mais do que os imediatos.

Os depoimentos de alunos e professores diferem. Para os alunos, a linguagem escrita serve para alcançar objetivos futuros, enquanto que para os professores essa aquisição está relacionada à possibilidade de seu usuário transformar a sociedade.

Diferentemente, na escola particular, a linguagem escrita é fundamentalmente considerada como um amplificador de habilidades intelectuais e secundariamente como servindo a objetivos acadêmicos (usos escolares). Tanto a funcionalidade como os usos estão envolvidos nas concepções sobre a linguagem escrita, na escola particular.

Os depoimentos de alunos e professores das escolas particulares também diferem: os alunos atribuem à linguagem escrita propósitos escolares (ganhos e usos imediatos, porém restritos), enquanto os professores percebem a linguagem escrita como um fator importante para o desenvolvimento de habilidades intelectuais (ganhos intelectuais).

Essa diferença entre a escola pública e a particular se reflete tanto entre alunos como entre professores. Os alunos das escolas públicas enfatizam a linguagem escrita como fator determinante para alcançar objetivos futuros a longo prazo (e.g., melhoria de vida, emprego). Os alunos das escolas particulares, por sua vez, atribuem à língua escrita usos acadêmicos (imediatos) e a percebem como fator importante para o desenvolvimento de habilidades intelectuais (e.g., melhorar o pensamento, ficar inteligente).

Os depoimentos dos professores apresentam pontos de semelhança e de divergência. A diferença básica reside na ênfase dada pelos professores das escolas públicas à possibilidade de transformar a sociedade mediante $\mathrm{o}$ 
tornar-se um cidadão letrado; ao passo que os professores das escolas particulares ressaltam a importância da língua escrita para o desenvolvimento cognitivo. O referencial para os professores das escolas públicas é, portanto, a sociedade (ganhos de caráter social e político); todavia, para o professor da escola particular, o referencial é o indivíduo (competências individuais). Nas duas escolas, a linguagem escrita é vista mais como um instrumento que pode fazer algo pelo indivíduo (função) do que como aquilo que o indivíduo pode fazer com ela (usos).

Essas divergências entre professores de escolas públicas e particulares trazem à tona uma questão bastante interessante: se diferentes concepções acerca dos usos e das funções da linguagem escrita gerariam diferentes expectativas do professor sobre o aluno, e quais as implicações que estas concepções têm na prática escolar alfabetizadora em cada escola.

Comparando os depoimentos de alunos e professores, de maneira geral, os alunos tendem a atribuir à linguagem escrita usos escolares e a percebê-la como um instrumento que lhes permitirá alcançar objetivos futuros. Para os professores, a aquisição da leitura e da escrita estaria relacionada à aquisição de habilidades intelectuais, não sendo percebida como algo que forneça ao seu usuário ganhos imediatos mais palpáveis. $\mathrm{E}$ importante notar que para os alunos a linguagem escrita nunca é concebida como algo que leve à obtenção de conhecimentos. Este tipo de concepção só aparece entre professores e, mesmo assim, de forma pouco expressiva. Este resultado está de acordo com aquele observado por Rockwell (1985).

A concepção do aluno de que a linguagem escrita se restringe aos usos escolares e que cumpre a função de instrumento para se obter ganhos futuros de caráter geral determina concepções que se distanciam da maneira de se conceber e usar a língua escrita com propósitos e funções sociais que propiciam ao seu usuário ganhos e usos imediatos relacionados às praticas sociais que envolvem a linguagem escrita em uma sociedade letrada.

Segundo Moreira (1988, p.37), a criança constrói esquemas interpretativos sobre a escrita "a partir do conhecimento da língua escrita, do conhecimento do mundo, do conhecimento dos objetos do mundo da 
escrita". Neste estudo, as concepções que, de maneira geral, as crianças mostraram ter acerca da linguagem escrita parecem não contribuir para que elas construam tais esquemas interpretativos. Muitas vezes, esses esquemas são favorecidos por atividades mais informais e assistemáticas, ocorridas no ambiente familiar do que na própria escola (Rego, 1988). Todavia, enquanto a criança de classe média pode construir esquemas interpretativos sobre a escrita, em seu contexto familiar, as crianças de classe baixa não têm em casa essa mesma chance (Carraher, 1986), sendo a escola o único local (ou, pelo menos, o mais freqüente) que, basicamente, proporciona a construção de tais esquemas. A escola pública, em especial, deveria refletir sobre tais diferenças e proporcionar situações significativas com a língua escrita, uma vez que no contexto familiar das crianças de baixa renda atos de leitura e escrita não fazem parte do cotidiano de suas vidas.

Para Luria ( 1983, p.276), "não é a compreensão que gera o ato, mas o ato é que faz nascer a compreensão". Em analogia, são os usos da língua escrita que geram a compreensão do sistema de escrita. Essa compreensão parece, portanto, requerer usos mais amplos da escrita, aspecto este que precisa ser considerado pela escola.

\section{Referências bibliográficas}

CARRAHER, Terezinha Nunes. Alfabetização e pobreza: três faces do problema. In: KRAMER, S. (Ed.). Alfabetização: dilemas da prática. Rio de Janeiro: Dois Pontos, 1986.

. Face-saving and literacy in Brazil. Sociological Abstracts, p.40-41, 1984.

HEATH, Shirley Brice. Ways with words: language, life, and work in communities and classrooms. Cambridge: Cambridge University Press, 1983.421p. 
HICKS, Deborah. Kinds of narrative. Genre skills among first graders from two communities. In: MCCABE, Allyssa, PETERSON, Carole (Ed.). Developing narrative structure. Hillsdale, NJ: Lawrence Earlbaum Associates, 1991. 367p.

LABOV, William. Language in the inner city. Philadelphia: University of Pensylvania Press, 1972.

LURIA, Alexander R. The development of writing in the child. In: MARTLEW, M. (Org.). The psychology of written language. Chichester: John Wiley and Sons, 1983.

MOREIRA, Nadja da Costa Ribeiro. Portadores de texto: concepções de crianças quanto a atributos, funções e conteúdo. In: KATO, Mary Aizawa (Org.). A concepção da escrita pela criança. São Paulo: Pontes, 1988. 206p.p. 15-52.

REGO, Lúcia Maria Lins Browne, Literatura infantil: uma nova perspectiva da alfabetização na pré-escola. São Paulo: FTD, 1988. 78p. (Por onde começar?).

ROCKWELL, E. Os usos escolares da língua escrita. Cadernos de Pesquisa, São Paulo, V.52, p.85-95, 1985.

SOARES, Magda B. A (des)aprendizagem das funções da escrita. Educação em Revista, n.8, p.3-11, 1988.

SPINILLO, Alina Galvão. Algumas dificuldades na aprendizagem da linguagem escrita em crianças de baixa renda. In: SIMPÓSIO DE PESQUISA E INTERCÂMBIO CIENTÍFICO DA ASSOCIAÇÃO NACIONAL DE PESQUISA E PÓS-GRADUAÇÃO EM PSICOLOGIA (ANPEPP), 5, 1994, Caxambu, MG. Resumos... 1994. p.49-50. 
SPINILLO, Alina Galvão, ALBUQUERQUE, Eliana Borges C. de, SILVA, Maria Emilia Lins e. A funcionalidade da língua escrita na escola pública e particular. In: REUNIÃO ANUAL DE PSICOLOGIA DA

SOCIEDADE BRASILEIRA DE PSICOLOGIA, 23, 1992,

Ribeirão Preto, SP. Resumos... 1992. p. 146.

SPINILLO, Alina Galvão, ROAZZI, Antonio. Usos e funções da língua escrita no contexto escolar. Revista Brasileira de Estudos Pedagógicos, Brasília, v.69, n.161, p.75-90, 1988.

Recebido em 17 de novembro de 1997.

Alina Galvão Spinillo, doutora em Psicologia do Desenvolvimento pela University of Oxford, Inglaterra, é professora adjunta do curso de pósgraduação em Psicologia, do Departamento de Psicologia da Universidade Federal de Pernambuco (UFPE).

Eliana Borges C. de Albuquerque, mestre em Psicologia pela Universidade Federal de Pernambuco (UFPE), é professora assistente do Departamento de Psicologia e Orientação Educacionais do Centro de Educação dessa universidade.

Maria Emilia Lins e Silva, mestre em Psicologia pela Universidade Federal de Pernambuco (UFPE), é professora assistente do Centro de Educação da Universidade Federal da Paraíba (UFPB).

Students ' and teachers ' point of view about the social uses and functions of written language was analysed. The results made it possible to identify several conceptions that differ between teachers and students, and also between public and private schools which attend children from different

R. bras. Est. pedag., Brasilia, v.11, n.187, p.477-496, set./dcz. 1996 
social backgrounds. The nature of these conceptions expresses different ideas about the social uses and functions of written language for the individual who learns how to write and read.

L 'opinion d'étudiants et enseignants de l'élémentaire sur les usages et fonctions du langage écrit a été analysée à partir d'interviews où la question centrale concernait les raisons de savoir lire et écrire. Différents points de vue ont été ainsi identifiés parmi les élèves et enseignants compte tenu de l'école (publique ou privée). Ces points de vue mettent en relief des différentes conceptions concernant $V$ usage et les fonctions du langage écrit pour l'individu qui apprend à lire et à écrire.

El testimonio de alumnos y profesores de alfabetización de escuelas públicas y particulares acerca de los usos y funciones del lenguaje escrito fue analisado a partir de entrevistas donde la pregunta central era "Para qué sirve leer y escribir? ". Através de los testimonios fue posible identificar diferentes concepciones, las cuales varían entre profesores y alumnos y en función del tipo de escuela. La naturaleza de esas concepciones refleja nociones distintas, respecto del uso y funciones del lenguaje escrito para el individuo que aprende a leer y a escribir. 